\title{
A Review of Intravesical Prostatic Protrusion in the Evaluation and Treatment of Benign Prostatic Enlargement
}

\author{
Balantine U. Eze, Okwudili C. Amu, and Jude A. Edeh
}

\section{ABSTRACT}

The evaluation of severity of symptoms, tracking complications, choosing effective and efficient approach to treatment, and prognosis is important in benign prostatic enlargement (BPE) patients. Measurement of intravesical prostatic protrusion (IPP) is an easy, affordable and non-invasive marker for benign prostatic obstruction with a high diagnostic value. This study aims to undertake a descriptive review of current literature for the role of IPP in the evaluation and treatment of patients with BPE. Relevant articles written in English language were retrieved from PubMed and Google Scholar. Keywords used for searching articles included intravesical prostatic Protrusion and Benign Prostatic Enlargement/ hyperplasia/ Obstruction; evaluation; and treatment. Papers published between January 1990 and October 2020 were extracted and evaluated. The analyzed studies showed that IPP can be assessed by various modalities and is important in the evaluation of symptom severity, tracking progression and complications of disease, choosing treatment option and prognostication. It is important that IPP be always assessed at the point of initial evaluation of BPE patients.

Keywords: Benign Prostatic Enlargement, Evaluation, Intravesical Prostatic Protrusion, and Treatment.

\section{INTRODUCTION}

In urology practice, benign prostatic enlargement (BPE) is a common problem among ageing men. The term BPE is used to describe the disease caused by benign prostatic hyperplasia (BPH) (which is actually a histologic diagnosis) as seen in the clinic [1]. The first challenge the urologist faces is to ascertain that a patient's lower urinary tract symptoms (LUTS) is due to BPE. After then, determining which investigations will help in evaluation of severity of symptoms, tracking complications, choosing effective and efficient approach to treatment, and prognosis becomes the next problem. The degree of bladder outlet obstruction (BOO) can indicate the severity of disease, aid in choosing a treatment option and in predicting treatment outcome [2].

Intravesical prostatic protrusion (IPP) is the extent to which the prostate protrudes into the bladder. IPP is produced by the median and/or lateral lobes and is measured on a sagittal image of the prostate from the tip of the protrusion to the base of the prostate where it joins the circumference of the base of the bladder [3]. IPP is an easily measurable non-invasive marker for Benign Prostatic Obstruction (BPO)[4]. Ultrasound measurement of IPP has greater diagnostic value in $\mathrm{BOO}$ than does total prostate volume (TPV) and many other non-invasive measures [5][11].

\author{
Published Online: January 13, 2021 \\ ISSN: 2593-8339 \\ DOI: $10.24018 /$ ejmed.2021.3.1.648 \\ B. U. Eze* \\ Department of Surgery, College of \\ Medicine, Enugu State University of \\ Science and Technology, Enugu, \\ Enugu State, Nigeria. \\ (e-mail: balantine.eze@esut.edu.ng) \\ O. C. Amu \\ Department of Surgery, College of \\ Medicine, University of Nigeria, \\ Enugu Campus, Enugu State, Nigeria. \\ (e-mail: amuokwy@yahoo.com) \\ J. A. Edeh \\ Department of Surgery, College of \\ Medicine, Enugu State University of \\ Science and Technology, Enugu, \\ Enugu State, Nigeria. \\ (e-mail: Anthony.edeh@esut.edu.ng) \\ *Corresponding Author
}

IPP is still underutilized in the evaluation of BPE patients. Despite the growing body of evidence that it can be a useful adjunct to urodynamics (which is invasive), the concept and use of IPP has been treated with skepticism by many urologists [7]. The aim of this article is to undertake a descriptive review of current literature for the role of IPP in the evaluation and treatment of patients with BPE.

\section{MATERIALS AND MethodS}

A search of relevant literature, published from January 1990 to October 2020, was carried out in PubMed and Google Scholar in October 2020. Only relevant articles published in English and in peer reviewed journals were selected for review. The search strategy included the key words "intravesical prostatic protrusion and benign prostatic enlargement/ hyperplasia/ obstruction; evaluation; and treatment." In addition, the references of each publication retrieved were scrutinized to look for other relevant studies. The abstracts of the articles were first reviewed and then, full texts of articles considered to be relevant were analyzed in depth. The first two authors had to agree for an article to be included. If they failed to reach an agreement, the third author was called in to help make a decision. 


\section{Methods Of Assessment Of IPP}

IPP cannot be assessed by routine digital rectal examination (DRE); unlike prostate volume that can be estimated by DRE [12]. Routine DRE fails to detect the configuration of IPP. IPP can be assessed by various imaging modalities including ultrasound, magnetic resonance imaging and computed tomography scan. IPP can also be measured with a flexible cystoscope [13]. Ultrasound is preferable because it is cheap, readily available, accurate, non-invasive and does not make use of ionizing radiation [14], [15]. Trans-abdominal route or trans-rectal ultrasound route can be used.

Measurement of IPP through trans-abdominal ultrasonography (TAUS) in the sagittal view is good as it is non-invasive, comfortable, easily available, cost-effective, and free of ionizing radiation [3]. For TAUS imaging of the prostate, an adequately filled bladder is essential; it acts as an acoustic window. An empty bladder makes ultrasound imaging and measurement of IPP difficult and unreliable [16]. Using TAUS, IPP is usually measured at bladder volume of 100-400mls, ideally 100-200 mls [16]. At a larger bladder volume (>400 ml), IPP may be underestimated due to the recession of the prostate behind the symphysis pubis [7]. Trans-rectal ultrasonography (TRUS), though more invasive and uncomfortable, may show less variation of IPP measurement with bladder volume [17]. Measurement via flexible cystoscope, though invasive, is least influenced by level of bladder filling than ultrasonography [13] and can also differentiate between a bilobar and a trilobar morphological pattern of enlargement [18]. Patients with trilobar enlargement tend to have significantly higher IPP, bladder contractility index and BOO index [18].

Considering the extent of protrusion into the bladder, IPP can be graded into: Grade I ( $<5 \mathrm{~mm})$; Grade II $(5-<10 \mathrm{~mm})$; and Grade III ( $\geq 10 \mathrm{~mm}$ ) [14], [19]. Grade I is mild, Grade II moderate and Grade III is considered significant, high grade or severe.

\section{SYMPTOM SEVERITY AND PROGRESSION}

The severity of BPE symptoms may not depend on the size of the prostate. In simple terms a huge prostate felt on DRE may have few non-bothering LUTS while a small prostate with significant IPP may cause acute retention (AUR) [20]. Disease progression in BPE is defined as PVR $>100 \mathrm{ml}$, AUR or deterioration of at least 4 points on International Prostate Symptom Score (IPSS) [21].

IPP has been shown to cause either more voiding symptoms due to ball-valve phenomenon or elongation of the prostatic urethra [22] or more storage symptoms due to increased bladder neck irritation by the protruding prostate tissue [23]. Men with more bothersome symptoms at enrollment are at higher risk of symptom progression and subsequently requiring Surgery [24]. The grade of IPP is strongly correlated to the clinical progression of $\mathrm{BPH}$ and urodynamic evidence of BOO [21]. IPP is a good predictor of BOO even in men with fairly good urinary flow (whose bladder is still able to produce enough pressure to overcome the infra-vesical obstruction) [10]. IPP $>5.5 \mathrm{~mm}$ have been shown to have a sensitivity of $66.7 \%$ and specificity of $80.5 \%$ for diagnosing BOO [5]. There is an increase in sensitivity $(75.5 \%)$ and specificity $(82.6 \%)$ at cutoff point of IPP of $7.5 \mathrm{~mm}$ [25].

Among all validated questionnaires used to assess severity of LUTS, the most used is the IPSS; and, it is an important tool used to characterize the severity of symptoms and to follow-up patients [26]. Though some studies [2], [27], [28] have not found significant correlation between IPSS and IPP, Most studies [3], [15], [21], [29]-[35] have found significant positive correlation between IPSS and IPP. Huang et al [2] not finding significant correlation between IPSS and IPP may be due to the method of categorization they used $(<10 \mathrm{~mm}, 10-20 \mathrm{~mm}$, >20mm); they still found significant positive correlation between IPSS voiding subscore and IPP. Lee et al [27] also found a significant positive correlation between IPSS storage sub-score and IPP.

IPP has been found to be an independent risk factor for BOO severity and could be a promising marker in clinical decision making at initial evaluation of BPE patients [36]. Patients with Grade III have the greatest likelihood of developing acute urinary retention or requiring BPH-related prostatic surgery, and thus may benefit from early surgical treatment [37]. Such patients may be counseled for surgery even at the point of initial evaluation.

\section{IPP AND BPE COMPLICATIONS}

Patients with LUTS tend to strain to pass urine and this may cause harm to the bladder and subsequently, the kidneys. Patients with significant IPP have increased symptoms which can predispose patients to complications. Currently there are not enough physiologic/ clinical studies on the secondary complications following significant IPP [12].

In a study to evaluate the risk for hydronephrosis in patients that had AUR before prostatectomy, Lu et al [38] found IPP grade III to be a significant risk factor for development of preoperative hydronephrosis and elevated serum creatinine. The IPP cut off point for highest risk of these complications was $19.5 \mathrm{~mm}$.

Huang et al [20] in a retrospective study to evaluate the risk of formation of bladder stones in BPE patients found that IPP $(\geq 10 \mathrm{~mm})$ was an independent risk factor for the presence of bladder calculi in patients with BPE. This has earlier been suggested by Kim et al [39] who also found length of IPP as the most important risk factor for formation of bladder stone in BPE patients (ahead of age and maximum flow rate).

Retrograde ejaculation can arise in patients with significant IPP by IPP affecting the integrity of the internal urethral sphincter via mechanical distension, thereby causing failure of the internal urethral sphincter to close during ejaculation [12]. Hence, patients with significant IPP have more incidence of pre-treatment retrograde ejaculation.

\section{IPP AND TREATMENT OPTIONS}

The aim of BPE treatment is to improve symptoms, improve patients quality of life and slow disease progression [13]. Therapeutic decision-making in BPE is usually guided by the severity of the symptoms, the degree of bother, and 
patient preference. IPP is not only helpful in assessing the severity of LUTS but can help in the choice of appropriate treatment modality [3].

The management of BPE includes watchful waiting/lifestyle modifications, pharmacotherapy, and surgery. Typically, the first rung of treatment is watchful waiting. At initial evaluation, the choice of appropriate treatment for men with BPE is important as patients with moderate symptoms who were managed initially with watchful waiting and progressed to needing surgery have worse outcomes than those that had surgery at the onset [40]. This is probably due to secondary bladder changes from prolonged obstruction.

Significant IPP has been found to be a predictor of failure of $\alpha$-blocker mono-therapy [10], [32], [41], $5 \alpha$-reductase mono-therapy [37] and even combination therapy [42]-[44]. Odd of success of $\alpha$-blocker therapy is 59 times higher in patients with mild IPP than in those with significant IPP [45]. Alpha-adrenoceptor antagonists are generally ineffective for treating IPP because IPP is a configuration of the prostate into the bladder above the bladder neck [7] and $\alpha$-receptors are mostly present inferior to the bladder neck (distal to the area of the protrusion) [12]. Combination therapy/ $\alpha$-reductase monotherapy has been found not to reduce the degree of IPP despite reduction in TPV and transitional zone volume [37], [42], [44]. Hence, patients with significant IPP will benefit more from surgery (open prostatectomy versus TURP); even when the prostate volume is small $(<30 \mathrm{mls})$ [46].

Patients with more IPP have been shown to benefit more from Holmium laser enucleation of the prostate (HoLEP) [47]. Also, Kim et al [13] and Park et al [48] found that patients with significant IPP benefit more than patients with non-significant IPP from Photoselective vaporization of the prostate (PVP). They had more significant early improvement in total IPSS, voiding IPSS sub-score and peak urinary flow rate. Wee et al [49] did not find any significant difference in improvement in IPSS between patients with IPP and those without IPP. However, there is agreement among these researchers that there is no significant difference in operative time, lasing energy and postoperative hospital stay due to IPP. More research needs to be done to settle this controversy of whether IPP affects outcomes following PVP.

Prostatic artery embolization (PAE) is a new technique for treatment of symptomatic BPE. It is carried out in the radiology department under local anesthesia. Meira et al [50] and Maron et al [51] did not find any correlation between outcome of treatment with PAE and degree of IPP. This means that PAE is equally effective for patients with IPP and those without IPP.

\section{IPP AND PROGNOSIS}

Not much work has been done in the area of investigating the impact of only IPP (without confounders) in prognosis following treatment of BPE patients. This is due to the confounding variables of the effects of prostate size, bladder contractility and anterior urethral curvature angle [36]. Zheng and colleagues [36], using three-dimensional models, and keeping other confounding variables constant, suggested that increasing IPP leads to deterioration of flow efficiency and could reduce the effectiveness of bladder outlet obstruction alleviation treatments.

Alpha-blocker treatment has been found to be more effective in patients with mild IPP than in those with moderate or severe IPP [14]. Patients with significant IPP are significantly more likely to fail trial-void-without catheter following the first episode of AUR with $\alpha$-blocker therapy [17], [52]-[54]. Generally, patients with significant IPP have worse outcome on either $\alpha$-blocker mono-therapy or combination therapy than those with mild IPP.

On the other hand, IPP may have a role in predicting the improvement in postoperative IPSS, quality of life (QoL), Qmax, and PVR [3], [55], [56]. It has also been shown that postoperative changes in IPSS and QoL score were higher in patients with IPP $\geq 5 \mathrm{~mm}$ than in the group with IPP $<5 \mathrm{~mm}$ [55], [57]. Patients with significant IPP have longer operative time during TURP [55].This suggests that patients with IPP do better than those without IPP (despite the longer operative time) following surgical treatment. Furthermore, significant IPP has also been shown to be a good predictor for postoperative improvement in hydronephrosis and renal function [38]. Hence, patients with significant IPP may benefit more from surgical therapy if surgery is performed early before irreparable renal damage.

With more recent treatment modalities, following treatment with PLP, Kim et al [13] and Wee et al [49] did not find any significant difference in postoperative complication between patients with IPP and those without IPP. On the other hand, following PAE, patients with higher IPP tend to have higher early postoperative complications and may need bailout surgery for de novo AUR [50], [58].

\section{CONCLUSION}

Compared to other non-invasive modalities, the advantages of IPP in assessing BPE include easy applicability, availability, low cost, and reliability. Therefore, there is room for a larger role for IPP in bedside assessment and management of BPE in daily practice. IPP measured by ultrasonography can help in assessing symptoms severity, disease progression, monitoring complications, choosing treatment options and predicting prognosis following treatment. Therefore, it is imperative that IPP be assessed by TAUS or TRUS at initial evaluation of BPE patients.

\section{REFERENCES}

[1] P. Abrams, L. Cardozo, M. Fall, D. Griffiths, P. Rosier, U. Ulmsten, and $e t a l$, "The standardisation of terminology in lower urinary tract function: report from the standardisation sub-committee of the International Continence Society," Urology, vol. 61, no. 1, pp. 37-49, Jan. 2003.

[2] T. Huang, J. Qi, Y. Yu, D. Xu, Y. Jiao, J. Kang, and et al, "Transitional zone index and intravesical prostatic protrusion in benign prostatic hyperplasia patients: correlations according to treatment received and other clinical data," Korean J. Urol., vol. 53, no. 4, pp. 253-257, Apr. 2012.

[3] G. B. Sigdel, and W. K. Belokar, "Clinical significance of intravesical prostatic protrusion in patients with benign prostatic hyperplasia," $J$. Univ. Coll. Med. Sci., vol. 3, no. 1, pp. 6-10, Sept. 2015.

[4] K. T. Foo, "Decision making in the management of benign prostatic enlargement and the role of transabdominal ultrasound," Int. J. Urol., vol. 17, no. 12, pp. 974-979, Dec. 2010. 
[5] S. H. Shin, J. W. Kim, J. W. Kim, M. M. Oh, and D. G. Moon, "Defining the degree of intravesical prostatic protrusion in association with bladder outlet obstruction," Korean J. Urol., vol. 54, no. 6, pp. 369-372, Jun. 2013.

[6] L. O. Reis, G. C. Barreiro, J. Baracat, A. Prudente, and C. A. D'Ancona, "Intravesical protrusion of the prostate as a predictive method of bladder outlet obstruction," Int. Braz. J. Urol., vol. 34, no. 5, pp. 627-637, Oct. 2008.

[7] T. L. Kuo, J. S. Teo, and K. T. Foo, "The role of intravesical prostatic protrusion (IPP) in the evaluation and treatment of bladder outlet obstruction (BOO)," Neurourol. Urodyn., vol. 35, no. 4, pp. 535-537, Apr. 2016.

[8] A. K. M. S. Hossain, A. K. M. K. Alam, A. K. M. K. Habib, M. M. Rashid, H. Rahman, A. K. M. A. Islam, and M. U. Jahan, "Comparison between prostate volume and intravesical prostatic protrusion in detecting bladder outlet obstruction due to benign prostatic hyperplasia" Bangladesh Med. Res. Counc. Bull., vol. 38, no. 1, pp. 14-17, Apr. 2012.

[9] D. Wang, H. Huang, Y. M. Law, and K. T. Foo, "Relationships between prostatic volume and intravesical prostatic protrusion on transabdominal ultrasound and benign prostatic obstruction in patients with lower urinary tract symptoms," Ann. Acad. Med. Singap., vol. 44, no. 2, pp. 60-65, Feb. 2015.

[10] A. Lee, H. J. Lee, K. B. Lim, H. H. Huang, H. Ho, and K. T. Foo, "Can intravesical prostatic protrusion predict bladder outlet obstruction even in men with good flow?," Asian J. Urol., vol. 3, no. 1, pp. 39-43, Jan. 2016

[11] S. K. Reddy, and A. B. Shaik, "Non-invasive evaluation of bladder outlet obstruction in benign prostatic hyperplasia: a clinical correlation study," Arab J. Urol., vol. 17, no. 4, pp. 259-264, Oct. 2019.

[12] J. Gandhi, S. J. Weissbart, A. N. Kim, G. Joshi, S. A. Kaplan, and S. A. Khan, "Clinical considerations for intravesical prostatic protrusion in the evaluation and management of bladder outlet obstruction secondary to benign prostatic hyperplasia," Curr. Urol., vol.12, no. 1, pp. 6-12, Oct. 2018.

[13] M. S. Kim, K. K. Park, B. H. Chung, and S. H. Lee, "Effect of photoselective vaporization prostatectomy on lower urinary tract symptoms in benign prostatic hyperplasia with or without intravesical prostatic protrusion," Korean J. Urol., vol. 54, no. 1, pp. 36-41, Jan. 2013.

[14] H. Y. Park, J. Y. Lee, S. Y. Park, S. W. Lee, Y. T. Kim, H. Y. Choi, and et al, "Efficacy of alpha blocker treatment according to the degree of intravesical prostatic protrusion detected by transrectal ultrasonography in patients with benign prostatic hyperplasia," Korean J. Urol. Vol. 53, no. 2, pp. 92-97, Feb. 2012.

[15] B. U. Eze, T. U. Mbaeri, C. K. Oranusi, J. A. Abiahu, A. M. Nwofor, J. C. Orakwe, and O. O. Mbonu, "Correlation between intravesical prostatic protrusion and international prostate symptom score among Nigerian men with benign prostatic hyperplasia," Niger. J. Clin. Pract., vol. 22, no. 4, pp. 454-459, Apr. 2019.

[16] S. P. Yuen, J. T. Ngiap, C. W. Cheng, and K. T. Foo, "Effects of bladder volume on transabdominal ultrasound measurement of intravesical prostatic volume," Int. J. Urol., vol. 9, no. 4, pp. 225-229, Apr. 2002.

[17] P. Mariappan, D. J. Brown, and A. S. McNeill, "Intravesical prostatic protrusion is better than prostate volume in predicting the outcome of trial without catheter in white men presenting with acute urinary retention: a prospective clinical study," J. Urol., vol. 178, no. 2, pp. 573-577, Aug. 2007.

[18] S. W. Lee, J. M. Cho, J. Y. Kang, and T. K. Yoo, "Clinical and urodynamic significance of morphological differences in intravesical prostatic protrusion," Korean J. Urol., vol. 51, no. 10, pp. 694-699, Oct. 2010.

[19] H. Nose, K. T. Foo, K. B. Lim, T. Yokoyama, H. Ozawa, and H. Kumon, "Accuracy of two noninvasive methods of diagnosing bladder outlet obstruction using ultrasonography: Intravesical prostatic protrusion and velocity-flow video urodynamics," Urology, vol. 65, no. 3, Mar. 2005.

[20] W. Huang, J. J. Cao, M. Cao, H. S. Wu, Y. Y. Yang, Z. M. Xu, and X.D. Jin, "Risk factors for bladder calculi in patients with benign prostatic hyperplasia," Medicine,vol. 96, no. 32, pp. e7728, Aug. 2017.

[21] L. S. Lee, H. G. Sim, K. B. Lim, D. Wang, and K. T. Foo, "Intravesical prostatic protrusion predicts clinical progression of benign prostatic enlargement in patients receiving medical treatment," Int. J, Urol., vol. 17, no. 1, pp. 69-74, Jan. 2010.

[22] C. K. Doo, and H. S. Uh, "Anatomic configuration of prostate obtained by noninvasive ultrasonography can predict clinical voiding parameters for determining BOO in men with LUTS." Urology, vol. 73 , no. 2, pp. 232-236, Feb. 2009.
[23] S.Yang, W. S. Hong, J. M. Lee, T. Kim, H. Chung, H. S. Kim, and et $a l$, "Is intravesical prostatic protrusion associated with predominant and intractable storage symptoms in BPH patients with over $30 \mathrm{~g}$ of prostate volume?," Neurourol. Urodyn., vol. 27, no. 7, pp. 580-581, Sept. 2008.

[24] P. Abrams, C. Chapple, S. Khoury, C. Roehrborn, and J. De la Rosette, "International consultation on new developments in prostate cancer and prostate diseases. Evaluation and treatment of lower urinary tract symptoms in older men," J. Urol., vol. 189, pp. S93S101, 2013.

[25] Z. Keqin, X. Zhishun, Z. Jing, W. Haixin, Z. Dongqing, and S. Benkang, "Clinical significance of intravesical prostatic protrusion in patients with benign prostatic enlargement." Urology, vol. 70, no. 6 , pp. 1096-1099, Dec. 2007.

[26] M. J. Barry, F. J. Fowler, M. P. O'Leary, R. C. Bruskewitz, H. L. Holtgrewe, W. K. Mebust, and et al, "The American Urological Association symptom index for benign prostatic hyperplasia," $J$. Urol., vol. 148, no.5, pp. 1549-1557, Nov. 1992.

[27] J. M. Lee, H. Chung, T. W. Kim, H. S. Kim, J. H. Wang, and S. K. Yang, "The correlation of intravesical prostatic protrusion with storage symptoms, as measured by transrectal ultrasound," Korean J. Urol., vol. 49, no. 2, pp. 145-149, Feb, 2008.

[28] C. P. Hou, Y. H. Lin, C. L. Chen, Y. L. Tsai, P. L. Chang, and K. H. Tsui, "Impact of the static prostatic urethral angle on men with lower urinary tract symptoms," Urol. Sci., vol. 27, no. 1, pp. 47-50, Mar. 2016.

[29] J. Tjahjodjati, and J. Santoso, "Relationship between prostate-urethral angle, intravesical prostatic protrusion, international prostatic symptom score, and uroflowmetry in benign prostatic hyperplasia patients," Int. J. Integr. Health Sci., vol. 3, no. 2, pp. 50-54, 2015.

[30] Y. M. Seo, and H. J. Kim, "Impact of intravesical protrusion of the prostate in the treatment of lower urinary tract symptoms/benign prostatic hyperplasia of moderate size by alpha receptor antagonist," Int. Neurourol. J., vol. 16. no. 4, pp. 187-190, Dec. 2012.

[31] S. Guneyli, E. Ward, Y. Peng, A. Nehal Yousuf, I. Trilisky, C. Westin, T. Antic, and A. Oto, "MRI evaluation of benign prostatic hyperplasia: correlation with international prostate symptom score," $J$. Magn. Reson. Imaging, vol. 45, no. 3, pp. 917-925, Mar. 2017.

[32] H. K. Park, G. Y. Choo, H. Chung, S. H. Paick, H. G. Kim, H. S. Kim, Y. S. Lho, W. S. Hong, and S. K. YANG, "Effect of intravesical prostatic protrusion on the characteristics of lower urinary tract symptom change after 12-week drug medication: a prospective analysis," Low. Urin. Tract Symptoms, vol. 5, no. 1, pp. 1-4, Jan. 2013.

[33] Y. J. Park, K. H. Bae, B. S. Jin, H. J. Jung, and J. S. Park, "Is increased prostatic urethral angle related to lower urinary tract symptoms in males with benign prostatic hyperplasia/lower urinary tract symptoms?," Korean J. Urol., vol. 53, no. 6, pp. 410-413. Jun, 2012.

[34] C. A. Agbo, V. M. Ramyil, N. K. Dakum, S. I. Shuaibu, V. E. Onowa, L. E. Nabasu, Z. Z. Galam, and B. C. Ukaonu, "The value of intravesical prostatic protrusion in evaluation of bladder outlet obstruction from benign prostatic enlargement in Nigeria," Afr. $J$. Urol., vol. 24, no. 4, pp. 342-346, 2018.

[35] M. A. Hossain, M. W. Islam, M. F. Naser, and M. S. Azam, "Correlation of international prostate symptom score With intravesical protrusion of prostate in patients with benign enlargement of prostate," Bangladesh J. Urol., vol. 22, no. 2, pp. 151-154, Nov. 2019.

[36] J. Zheng, J. Pan, Y. Qin, J. Huang, Y. Luo, X. Gao, and X. Zhou, "Role for intravesical prostatic protrusion in lower urinary tract symptom: a fluid structural interaction analysis study," BMC Urol., vol. 15 , no. 1, pp. 86-86, Dec. 2015. https://doi.org/10.1186/s12894015-0081-y

[37] T. Yoshida, H. Kinoshita, K. Yoshida, T. Mishima, H. Taniguchi, M. Yanishi, Y. Komai, K. Yasuda, M. Sugi, and T. Matsuda, "Intravesical prostatic protrusion as a predicting factor for the adverse clinical outcome in patients with symptomatic benign prostatic enlargement treated with dutasteride," Urology, vol.91, pp. 154-157, 2016.

[38] C. H. Lu, H. H. Wu, T. P. Lin, Y. H. Huang, H. J. Chung, J. Y. Kuo, W. J. Huang, S. H. Lu, Y. H. Chang, and A. T. Lin, "Is intravesical prostatic protrusion a risk factor for hydronephrosis and renal insufficiency in benign prostate hyperplasia patients?, J. Chin. Med. Assoc., vol. 82, no. 5, pp. 381-384, May 2019.

[39] J. W. Kim, M. M. Oh, H. S. Park, J. Cheon, J. G. Lee, J. J. Kim, and D. G. Moon, "Intravesical prostatic protrusion is a risk factor for bladder stone in patients with benign prostatic hyperplasia," Urology, vol. 84, no. 5, pp. 1026-1029, Nov. 2014.

[40] R. C. Flanigan, D. J. Reda, J. H. Wasson, R. J. Anderson, M. Abdellatif, and R. C. Bruskewitz, "5-year outcome of surgical 
resection and watchful waiting for men with moderately symptomatic benign prostatic hyperplasia: a Department of Veterans Affairs cooperative study," J. Uro., vol. 160, no. 1, pp. 12-17, Jul. 1998.

[41] A. Ahmed, "Sonographic parameters predicting the outcome of patients with lower urinary tract symptoms/benign prostatic hyperplasia treated with alpha1-adrenoreceptor antagonist," Urology, vol. 88, pp. 143-148, Nov. 2016.

[42] Q. Liu, Y. Zhu, J. Liu, J. Qi, and J. Kang, "Ultrasound image features of intravesical prostatic protrusion indicated failure of medication therapy of finasteride and doxazosin in patients with benign prostatic hyperplasia (LUTS/BPH)," Int. Urol. Nephrol., vol. 49, no. 3, pp. 399-404, Mar. 2017.

[43] K. Hirayama, K. Masui, A. Hamada, Y. Shichiri, N. Masuzawa, and S. Hamada, "Evaluation of intravesical prostatic protrusion as a predictor of dutasteride-resistant lower urinary tract symptoms/benign prostatic enlargement with a high likelihood of surgical intervention," Urology, vol. 86, no. 3, pp. 565-569, Sep. 2015.

[44] R. T. Puthenveetil, D. Baishya, S. Barua, and D. Sarma, "Implication of ultrasound bladder parameters on treatment response in patients with benign prostatic hyperplasia under medical management," Asian J. Urol., vol. 2, no. 4, pp. 233-237, Oct. 2015.

[45] Y. H. Tan, and K. T. Foo, "Intravesical prostatic protrusion predicts the outcome of a trial without catheter following acute urine retention," J. Urol., vol. 170, no. 6, pp. 2339-2341, Dec. 2003.

[46] X. D. Li, Y. P. Wu, Z. B. Ke, T. T. Lin, S. H. Chen, X. Y. Xue, N. $\mathrm{Xu}$, and $\mathrm{Y}$. Wei, "Predictors of postoperative lower urinary tract symptoms improvements in patient with small-volume prostate and bladder outlet obstruction," Ther. Clin. Risk Manag., vol. 15, pp. 1291-1304, Nov. 2019.

[47] X. Chen, Q. Man, X. Wei, X. Ren, G. Li, Z. Lu, X. Zhang, and C. Qin, "Predictive value of preoperative comprehensive evaluation on the efficacy of HoLEP," Transl. Androl. Urol., vol. 9, no. 4, pp. $1603-$ 1610, Aug. 2020.

[48] J. Park, C. H. Park, I. Sun, S. Y. Cho, M. C. Cho, H. Jeong, and H. Son, "Preoperative transrectal ultrasonographic findings can predict the improvement of the peak urinary flow rate after surgical treatment of benign prostatic enlargement in patients with lower urinary tract symptoms," J. Urol., vol. 197, no. 4S, pp. e513-514, Apr. 2017.

[49] J. H. Wee, Y. S. Choi, W. J. Bae, S. J. Kim, H. J. Cho, S. H. Hong, J. Y. Lee, and S. W. Kim, "Influence of intravesical prostatic protrusion on preoperative lower urinary tract symptoms and outcomes after 120 w high performance system laser treatment in men with benign prostatic hyperplasia," Korean J. Urol., vol. 53, no. 7, pp. 472-477, Jul. 2012.

[50] M. Meira, A. M. de Assis, A. M. Moreira, A. A. Antunes, F. C. Carnevale, and M. Srougi, "Intravesical prostatic protrusion does not influence the efficacy of prostatic artery embolization" J. Vasc. Interv. Radiol., vol.32, no. 1, pp. 106-112, Jan. 2021.

[51] S. Z. Maron, A. Sher, J. Kim, R. A. Lookstein, A. R. Rastinehad, and A. Fischman, "Effect of median lobe enlargement on early prostatic artery embolization outcomes," J. Vasc. Interv. Radiol., vol. 31, no. 3, pp. 370-377, Mar. 2020.

[52] L. Topazio, C. Perugia, C. De Nunzio, G. Gaziev, V. Iacovelli, D. Bianchi, G. Vespasiani, and E. F. Agrò, "Intravescical prostatic protrusion is a predictor of alpha blockers response: results from an observational study," BMC urol., vol. 18, no. 1, pp. 1-5, Dec. 2018.

[53] O. S. Sharis, M. Z. Zulkifli, and A. H. Hamzaini, "Predicting outcome of trial of voiding without catheter in acute urinary retention with intravesical prostatic protrusion" Malays. J. Med. Sci., vol. 20, no. 1, pp. 56-59, Jan. 2013.

[54] H. Y. Tiong, M. J. Tibung, M. Macalalag, M. K. Li, and D. Consigliere, "Alfuzosin $10 \mathrm{mg}$ once daily increases the chances of successful trial without catheter after acute urinary retention secondary to benign prostate hyperplasia" Urol. Int., vol. 83, no. 1, pp. 44-48, Jul. 2009.

[55] Z. Liu, J. Chen, and Q. Lu Q, "Impact of intravesical prostatic protrusion and pathological type on transurethral resection of the prostate for benign prostatic hyperplasia." Biomed. Res., vol. 28, no. 9, pp. 8367-8371, Sept. 2017.

[56] T. Huang, J. Qi, Y. J. Yu, D. Xu, Y. Jiao, J. Kang, Y. Q. Chen, and Y. K. Zhu, "Predictive value of resistive index, detrusor wall thickness and ultrasound estimated bladder weight regarding the outcome after transurethral prostatectomy for patients with lower urinary tract symptoms suggestive of benign prostatic obstruction," Int. J. Urol., vol. 19, no. 4, pp. 343-350, Apr. 2012.

[57] J. W. Lee, J. H. Ryu, T. K. Yoo, S. S. Byun, Y. J. Jeong, and T. Y. Jung, "Relationship between intravesical prostatic protrusion and postoperative outcomes in patients with benign prostatic hyperplasia," Korean J. Urol., vol. 53, no. 7, pp. 478-482, Jul. 2012.

[58] S. C. H. Yu, C. C. M. Cho, E. H. Y. Hung, J. Zou, B. T. Y. Yuen, L. Shi, and et al, "Thickness-to-height ratio of intravesical prostatic protrusion predicts the clinical outcome and morbidity of prostatic artery embolization for benign prostatic hyperplasia," J. Vasc. Interv. Radiol., vol. 30, no. 11, pp. 1807-1816, Oct. 2019. 